\title{
Speciation, Species Delineation, and Electrophoretic Isoenzyme Patterns of the Type Strains of Kluyveromyces van der Walt emend. van der Walt
}

\author{
DEBORAH G. SIDENBERG AND MARC-ANDRÉ LACHANCE* \\ Department of Plant Sciences, University of Western Ontario, London, Ontario, N6A 5B7, Canada
}

\begin{abstract}
The type strains of the 20 species of the yeast genus Kluyveromyces sensu van der Walt 1970 were studied by gel electrophoresis of 11 isofunctional enzymes. These enzymes included five oxidoreductases (alcohol dehydrogenase [EC 1.1.1.1], lactate dehydrogenase [EC 1.1.1.27], malate dehydrogenase [EC 1.1.1.37], catalase [EC 1.11.1.6], and superoxide dismutase [EC 1.15.1.1]), five hydrolases (esterase [EC 3.1.1.1], alkaline phosphatase [EC 3.1.3.1], $\alpha$-glucosidase [EC 3.2.1.20], $\beta$-glucosidase [EC 3.2.1.21], and exo- $\beta$-glucanase [EC 3.2.1.58]), and one lyase (aldolase [EC 4.1.2.12]). Polymorphism was evident in most of the enzymes studied. Each type strain had a unique pattern when all enzymes were considered. The results of a multivariate analysis of the electrophoretic patterns supported the division of the genus into 13 species, 2 of which comprised four and five taxa, respectively, which were recognized in 1970. Enzyme electrophoresis provided evidence that widespread gene flow does not necessarily occur between yeasts which are able to hybridize in the laboratory.
\end{abstract}

Protein electrophoresis and isoenzyme electrophoresis have been used to study the population genetics, biosystematics, evolutionary biology, and biochemistry of the enzymes of a wide range of life forms. Electrophoretic studies of fungi have concentrated on ascomycetous genera (8) and have demonstrated multiple molecular forms for certain enzymes. Few studies have been done on yeasts. In some cases $(1,2,20)$, electrophoresis has been useful in clarifying taxonomic relationships. A few investigators have studied selected members of the genus Kluyveromyces van der Walt emend. van der Walt $(4,5,7,16)$.

The genus Kluyveromyces is of special interest because its phenetic structure (15), deoxyribonucleic acid (DNA) reassociation patterns (13; H. J. Phaff, M. A. Lachance, and H. L. Presley, Abstr. 12th Int. Congr. Microbiol., Munich, Germany, 1978, abstr. no. S27.3), and mating compatibility patterns (11) are rather well defined. There have been disagreements as to which of the last two criteria should prevail in delineating Kluyveromyces species $(14,19)$. Enzyme electrophoresis patterns should be useful in determining whether gene flow is effectively operative among taxa which are able to form hybrids but which have diverged genetically, as indicated by low degrees of DNA reassociation.

In this paper, we describe an electrophoretic survey of 11 enzymes, which was undertaken to determine the extent of heterogeneity within Kluyveromyces and to identify the different iso- enzyme patterns in the type strains of the species recognized by van der Walt (18). Our results may indicate the enzymes most useful in studies of gene flow in natural populations of selected Kluyveromyces species. The taxonomic relevance of electrophoresis is examined, with particular reference to the possible correlations between electrophoretic patterns and the different criteria used to delineate yeast species.

\section{MATERIALS AND METHODS}

Microorganisms. The type strains of the Kluyveromyces species listed in Table 1 were obtained from H. J. Phaff, Department of Food Science and Technology, University of California, Davis. These organisms were maintained on yeast extract-malt extract-glucose-peptone agar at $4^{\circ} \mathrm{C}$ in screw-capped vials.

Preparation of extracts. Cultures were grown on yeast extract-malt extract-glucose-peptone agar for 3 days at $25^{\circ} \mathrm{C}$. In the case of a potentially inducible enzyme, each strain was grown to late exponential phase in yeast extract-malt extract-glucose-peptone broth in which the glucose was replaced by the appropriate substrate. Flasks were incubated at $25^{\circ} \mathrm{C}$ on a reciprocal shaker. For $\alpha$-glucosidase the substrates were $0.3 \%$ maltose, $0.3 \%$ melezitose, $0.3 \%$ methyl- $\alpha$ D-glucoside, and $0.3 \%$ dextrin, or $0.3 \%$ trehalose. The medium for $\beta$-glucosidase contained $0.3 \%$ arbutin.

Cells were disrupted with 0.5 -mm glass beads in a vortex mixer for $3 \mathrm{~min}$ in $0.05 \mathrm{M}$ sodium succinate buffer ( $\mathrm{pH} 5.5$ ) with occasional chilling in ice. Homogenates were centrifuged at $10,000 \times g$ for $10 \mathrm{~min}$, and supernatants were decanted. Protein extracts were stored at $-20^{\circ} \mathrm{C}$. Extracts for alkaline phosphatase were unstable to freezing and therefore were prepared 
fresh for each experiment. The addition of various protease inhibitors during extraction was investigated and found to be unnecessary.

Chemicals. Electrophoresis grade acrylamide, $N, N^{\prime}$ methylenebisacrylamide, $N, N, N^{\prime}, N^{\prime}$-tetramethyl-enediamine, tris(hydroxymethyl)aminomethane, glycine, and ammonium peroxydisulfate were purchased from Bio-Rad Laboratories, Richmond, Calif. Bromophenol blue and guaiacol were obtained from British Drug House, Toronto, Ontario, Canada. Laminaran was obtained from United States Biochemical Corp., Cleveland, Ohio. Benzidine, fast blue RR salt, peroxjdase, glucose oxidase, glyceraldehyde-3-phosphate dehydrogenase, $\alpha$-naphthyl acetate, agarose, phenazine methosulfate, 3[4,5-dimethylythiazoyl-2-yl]2,5diphenyl tetrazolium bromide, nicotinamide adenine dinucleotide, arbutin, maltose, $\alpha$-methyl-D-glucoside, trehalose, and fructose 1,6-diphosphate were purchased from Sigma Chemical Co., St. Louis, Mo. All other chemicals were of reagent grade.

Agarose gel electrophoresis. Agarose gels were used for catalase, since visualization of this enzyme on polyacrylamide gels is impractical. These gels contained $0.7 \%$ agarose, $0.3 \%$ starch, $0.021 \mathrm{M}$ tris(hydroxymethyl)aminomethane, $0.015 \mathrm{M}$ boric acid, and $0.0006 \mathrm{M}$ ethylenediaminetetraacetate and were adjusted to $\mathrm{pH} 8.0$. The bridge buffer was $10 \times$-concentrated gel buffer. Electrophoresis was conducted at $4^{\circ} \mathrm{C}$ and $12 \mathrm{~mA}$ for $2 \mathrm{~h}$.

Polyacrylamide gel electrophoresis. Discontinuous nondenaturing polyacrylamide gels were prepared as recommended by Davis (3). The stacking gels and the running gels contained tris(hydroxymethyl)aminomethane hydrochloride buffer at concentrations of 0.06 and $0.38 \mathrm{M}$, respectively; the $\mathrm{pH}$ values of these gels were 6.9 and 8.9 , respectively. The electrode buffer contained $0.05 \mathrm{M}$ tris(hydroxymethyl)aminomethane and $0.38 \mathrm{M}$ glycine $(\mathrm{pH} 8.3)$. The concentrations of the gels varied with the enzymes studied. For $\beta$-glucosidase, esterase, aldolase, $\alpha$-glucosidase, and exo- $\beta$-glucanase, the acrylamide concentrations in the stacking and running gels were 3.0 and 5.0,3.0 and 7.7, 5.0 and $7.0,5.0$ and 10.0 , and 5.0 and $12.0 \%$, respectively. Single-concentration gels containing $7.7 \%$ acrylamide were used for all dehydrogenases, superoxide dismutase, and alkaline phosphatase.

Electrophoresis was conducted in the cold under constant currents between 15 and $30 \mathrm{~mA}$ to produce running times of 4 to $5 \mathrm{~h}$ without excessive heating. The sample volumes were varied to give optimal resolution. Generally, between 20 and $60 \mu \mathrm{l}$ of crude protein extracts was used. Nine samples were applied to each gel slab. The relative mobilities ( $\boldsymbol{R}_{f}$ values) were calculated with reference to the dye front or, for catalase, with reference to the dominant electromorph (the fast band of Kluyveromyces marxianus was used as a standard on each catalase gel). All electromorphs were scored on a presence-or-absence basis, and we made no assumptions as to the individual genetic bases. All samples were studied at least twice for each enzyme.

Histochemical staining. Exo- $\beta$-glucanase, $\alpha$-glucosidases, and $\beta$-glucosidase were visualized by a histochemical method as described elsewhere (16). The substrate concentration for $\beta$-glucosidase was $3 \%$. The specificity of $\alpha$-glucosidases was determined by developing gels separately with $\alpha$-methyl-D-glucoside, malt- ose, or trehalose as the substrate, but the $R_{f}$ values of these enzymes were determined by staining simultaneously with combined substrates. Arbutinase and trehalase were also stained by the method of Eilers et al. (6). Esterase, catalase, lactate, malate and alcohol dehydrogenases, superoxide dismutase, and alkaline phosphatase were stained by the methods of Harris and Hopkinson (9). Catalase gels were examined immediately after hydrogen peroxide was added, as the bands spread rapidly. All other gels were incubated overnight in their staining mixtures.

Data analysis. The amount of information provided by each enzyme was evaluated by the following entropy $\left(I_{j}\right)$ measure:

$$
\begin{gathered}
I_{j}=\left(n \times t_{j} \times \ln t_{j}\right) \\
-\sum_{i=1}^{n}\left[\left(a_{i j} \times \ln a_{i j}\right)+\left(t_{j}-a_{i j}\right) \times \ln \left(t_{j}-a_{i j}\right)\right]
\end{gathered}
$$

where $n$ is the number of strains (in this case, 20 strains), $t_{j}$ is the total number of different electromorphs for the $j$ th enzyme, and $a_{i j}$ is the number of electromorphs of that enzyme present in the $i$ th strain (17). For multivariate analysis, the results were expressed in a matrix having the dimensions $n \times p$, where $n$ (i.e., 20) strains are described by the presence (scored as 1) or absence (scored as 0 ) of each of $p$ (i.e., 96) electromorphs. Reciprocal averaging (10) was used to ordinate the strains as a function of correlated electromorphs.

\section{RESULTS AND DISCUSSION}

Taxonomic structure of Kluyveromyces. The genus Kluyveromyces has been the subject of several taxonomic investigations since its latest detailed revision by van der Walt (18). The different group structures proposed by various workers are given in Table 1 . Basing her structure on phenotypic resemblance, Poncet (15) divided the genus into two fundamental clusters. Group A comprised a number of nutritionally restricted taxa that were isolated mostly from soils. Group B contained taxa that were associated with various habitats and was divided into two subsets, which were distinguished by their growth responses on $\alpha$-glucosides (subgroup B2 taxa utilized these carbohydrates more extensively than subgroup B1 taxa). Poncet viewed Kluyveromyces wickerhamii and Kluyveromyces phaseolosporus as transitional forms between subgroups B1 and B2 and Kluyveromyces thermotolerans (synonym, Kluyveromyces veronae) as a nonmember of the genus. DNA reassociation studies (13; Phaff et al., Abstr. 12th Int. Congr. Microbiol.) gave results which partially agreed with the conclusions of Poncet (15). Such studies indicated high degrees of genetic homogeneity among Kluyveromyces lactis, Kluyveromyces vanudenii, K. phaseolosporus, and Kluyveromyces drosophilarum and among $K$. marxianus, Kluyveromyces wikenii, Kluyvero- 
TABLE 1. Nomenclature and proposed groupings of Kluyveromyces type strains

\begin{tabular}{|c|c|c|c|c|}
\hline \multirow[b]{2}{*}{$\begin{array}{l}\mathrm{UCD}(\mathrm{FS} \& \mathrm{~T}) \\
\text { no. }{ }^{a}\end{array}$} & \multirow[b]{2}{*}{ Taxonomic designation } & \multicolumn{3}{|c|}{ Grouping by: } \\
\hline & & $\begin{array}{l}\text { Phenetic } \\
\text { similarity }\end{array}$ & DNA reassociation & Hybridization $^{d}$ \\
\hline $61-29^{\mathrm{T}}$ & K. aestuarii (Fell) van der Walt 1961 & $\mathrm{~B} 2$ & K. aestuarii & K. aestuarii \\
\hline $70-4^{T}$ & $\begin{array}{l}K . \text { vanudenii (van der Walt et Nel) van der } \\
\text { Walt } 1963\end{array}$ & $\mathrm{~B} 2$ & K. lactis & K. marxianus \\
\hline $50-80^{\mathrm{T}}$ & $\begin{array}{l}\text { K. phaseolosporus (Shehata, Mrak, et Phaff) } \\
\text { van der Walt } 1955\end{array}$ & B1-B2 & K. lactis & K. marxianus \\
\hline $71-59^{\mathrm{T}}$ & K. lactis (Dombrowski) van der Walt 1910 & B2 & K. lactis & K. marxianus \\
\hline $51-130^{\mathrm{T}}$ & $\begin{array}{l}K . \text { drosophilarum (Shehata, Mrak, et Phaff) } \\
\text { van der Walt } 1955\end{array}$ & B2 & K. lactis & K. marxianus \\
\hline $50-45^{\mathrm{T}}$ & $\begin{array}{l}\text { K. dobzhanskii (Shehata, Mrak, et Phaff) van } \\
\text { der Walt } 1955\end{array}$ & B2 & $K$. dobzhanskii & K. marxianus \\
\hline $71-15^{\mathrm{T}}$ & K. wikenii van der Walt, Nel, et Kerken 1966 & B1 & K. marxianus & K. marxianus \\
\hline $71-58^{\mathrm{T}}$ & K. fragilis (Jorgensen) van der Walt 1909 & B1 & K. marxianus & K. marxianus \\
\hline $55-82^{\mathrm{T}}$ & K. marxianus (Hansen) van der Walt 1888 & $\mathrm{~B} 1$ & K. marxianus & K. marxianus \\
\hline $71-14^{\mathrm{T}}$ & $\begin{array}{l}\text { K. cicerisporus van der Walt, Nel, et Kerken } \\
1966\end{array}$ & $\mathrm{~B} 1$ & K. marxianus & K. marxianus \\
\hline $71-13^{\mathrm{T}}$ & K. bulgaricus (Santa Maria) van der Walt 1956 & $\mathrm{~B} 1$ & K. marxianus & K. marxianus \\
\hline $72-13^{\mathrm{T}}$ & K. waltii Kodama 1974 & $-e$ & $-e$ & (K. marxianus) \\
\hline $54-210^{\mathrm{T}}$ & $\begin{array}{l}\text { K. wickerhamii (Phaff, Miller, et Shifrine) van } \\
\text { der Walt } 1956\end{array}$ & B1-B2 & K. wickerhamii & (K. marxianus) \\
\hline $55-41^{\mathrm{T}}$ & K. thermotolerans (Philippov) Yarrow 1932 & $\mathbf{N}$ & K. thermotolerans & (K. marxianus) \\
\hline $70-5^{\mathrm{T}}$ & K. phaffii (van der Walt) van der Walt 1963 & A & (K. phaffii) & K. phaffii \\
\hline $57-17^{\mathrm{T}}$ & $K$. polysporus van der Walt 1956 & A & K. polysporus & K. polysporus \\
\hline $56-2^{\mathrm{T}}$ & $\begin{array}{l}K . \text { delphensis (van der Walt et Tscheuschner) } \\
\text { van der Walt } 1956\end{array}$ & A & (K. delphensis) & K. delphensis \\
\hline $70-3^{\mathrm{T}}$ & $\begin{array}{l}K . \text { lodderi (van der Walt et Tscheuschner) van } \\
\text { der Walt } 1957\end{array}$ & A & (K. lodderi) & K. lodderi \\
\hline $77-7^{\mathrm{T}}$ & K. blattae Henninger et Windish 1976 & - & $-^{e}$ & K. blattae \\
\hline $57-16^{\mathrm{T}}$ & K. africanus van der Walt 1956 & A & (K. africanus) & K. africanus \\
\hline
\end{tabular}

${ }^{a} \mathrm{UCD}(\mathrm{FS} \& \mathrm{~T})$, Culture collection of the Department of Food Science and Technology, University of California, Davis. $\mathrm{T}=$ type strain.

${ }^{b}$ From reference 15 .

${ }^{c}$ From reference 13 and the work of Phaff et al. (Abstr. 12th Int. Congr. Microbiol.). Parentheses indicate uncertain affiliation.

${ }^{d}$ From reference 11 . Parentheses indicate low levels of hybridization.

${ }^{e}$ Strains not available at the time when the studies were performed.

myces fragilis, Kluyveromyces cicerisporus, and Kluyveromyces bulgaricus. Johannsen (11) examined the ability of Kluyveromyces strains to form hybrids with combined parental phenotypes. A total of 10 taxa showed relatively high levels of mating intercompatibility, and for this reason these organisms were considered to represent varieties of a single species, K. marxianus. Three other taxa (Table 1) hybridized less extensively with some of these putative varieties and were therefore maintained as separate but related species. The remaining seven species were recognized as reproductively isolated.

Electrophoretic patterns. The 20 type strains of Kluyveromyces species exhibited considerable heterogeneity with respect to electrophoretic patterns (Fig. 1). The various enzymes differed in the amount of information which each could provide, as evidenced by the entropy values, which ranged from 8 to 185 . Amylase, $\beta$ galactosidase, $\beta$-fructosidase, hexokinase, glu- cose dehydrogenase, and protease were also examined. These enzymes did not provide reproducible results due to poor extractability or stability and were not considered further.

Dehydrogenases (Fig. 1A through $\mathrm{C}$ ) had intermediate entropy values. A number of electromorphs were shared by all members of the $K$. marxianus mating compatibility group; however, some electromorphs were found exclusively in members of either the $K$. lactis subgroup or the $K$. marxianus subgroup, as defined by DNA complementarity (Table 1). For most enzymes, Kluyveromyces waltii and $K$. bulgaricus were very similar, and Kluyveromyces aestuarii was unique. Several members of phenetic group A lacked activity for some dehydrogenases.

Catalase (Fig. 1D) exhibited little variation. One electromorph was common to 19 of the 20 strains tested. It should be pointed out that the agarose gels used for this enzyme were less discriminatory than polyacrylamide gels. Sever- 
al strains showed a second electromorph whose distribution did not follow any recognizable pattern. Again, $K$. aestuarii was unique. $K$. waltii and $K$. bulgaricus were identical.

Despite the rather high entropy of superoxide dismutase (Fig. 1E), this enzyme produced patterns which were highly consistent with the DNA reassociation groupings (Table 1). Of interest was the apparent intermediate status of Kluyveromyces dobzhanskii, which shared electromorphs found in either the $K$. lactis DNA subgroup or the $K$. marxianus DNA subgroup. Once more, $K$. aestuarii appeared to be unique.

Esterase (Fig. $1 \mathrm{~F})$ was the most variable $\left(I_{j}\right.$, 185 ) enzyme studied. The patterns were distinct for all strains. Most strains in the $K$. marxianus DNA subgroup (Table 1) produced considerably more electromorphs than their $K$. lactis subgroup counterparts, with little overlap between the two subgroups.

Aldolase activity (Fig. 1G) was absent in more than one-half of the strains. One of the electromorphs of this enzyme was shared by all members of phenetic subgroup B2 (Table 1), including $K$. aestuarii, a rare occurrence.

Alkaline phosphatase (Fig. 1H) activity was not detected in the $K$. lactis subgroup (Table 1). The strains in phenetic group B1 (equivalent to the $K$. marxianus DNA subgroup) had overlapping patterns that were somewhat suggestive of a population which was heterozygous for a biallelic locus.

Glucosidases must be viewed differently from other enzymes. Kluyveromyces species may vary in their utilization of glucosides (18). The slow $\left(R_{f},<0.4\right)$ electromorphs of $\alpha$-glucosidase (Fig. 11) were particularly active in the hydrolysis of trehalose. Two of these electromorphs were sporadically found throughout the genus, a third was unique to three members of the $K$. marxianus DNA subgroup (Table 1), and a fourth was unique to Klayveromyces lodderi. $K$. thermotolerans produced, among others, an electromorph that was more specific toward $\alpha$ methyl-D-glucoside $\left(R_{f}, 0.43\right)$. A single electromorph with maximum activity on maltose was present in maltose-utilizing members of the $K$. lactis DNA subgroup.

Members of the $K$. marxianus DNA subgroup produced up to three $\beta$-glucosidase forms (Fig. $1 \mathrm{~J})$, one of which was also present in two strains of the $K$. lactis subgroup. The very low entropy of this enzyme reflected not only its lack of variability, but also its rarity in the genus.

Exo-B-glucanase (Fig. 1K) has been discussed previously (16); the results are shown here for comparison. The presence of electromorphs typical of both the $K$. marxianus and $K$. lactis subgroups in $K$. drosophilarum and the uniqueness of $K$. aestuarii are indeed striking.
The data described above indicate that further studies of polymorphism in natural populations of Kluyveromyces would be best directed at enzymes such as dehydrogenases, superoxide dismutase, esterase, and exo- $\beta$-glucanase. These enzymes were present in all of the members of $K$. marxianus mating compatibility group (Table 1), and their varying degrees of polymorphism should allow strain characterization over a broad range of heterogeneity.

Speciation and species delineation. Yeast taxonomists generally regard the species as a special taxonomic category. Most go along with the notion that reproductive isolation is the fundamental criterion upon which species may be meaningfully delineated. They do differ, however, in their choices of methodologies by which commonality of gene pools may be determined. Phaff (14) discussed this matter, emphasizing that conspecificity requires many elements. First, chromosomal DNA complementarity is required to allow viable recombination to occur between strains. Equally important is mating compatibility, which is necessary for genomes to interact physically. Finally, habitats in common are essential for mating to occur at frequencies high enough to allow significant gene exchange among natural populations.

In Kluyveromyces, genome compatibility and mating compatibility are rather well defined (Table 1). Although ecological specificity is less well understood, it is logical to assume that phenetic affinities (Table 1) are major determinants of the ecological distribution of Kluyveromyces species. The electrophoretic patterns presented here may offer a means of verifying gene flow a posteriori. Indeed, many electromorphs represent independent genes that are expected to covary as a function of reproductive continuity. For example, if the $K$. marxianus mating group is effectively syngamic (11), then the distribution of electromorphs among its members should be more or less continuous. Conversely, if among several electromorphs there are strong correlations and sharp discontinuities which are consistent with genome complementarity patterns as identified by DNA reassociation, then it must be concluded that the relevant groups are members of reproductively isolated populations.

To answer these questions, the electrophoretic data were subjected to multivariate analysis by means of reciprocal averaging. This eigenanalysis method ordinates both individuals and variables as a function of their canonical (reciprocal) correlations. The ordination of Kluyveromyces type strains on canonical axes 2 and 4 is shown in Fig. 2. The first axis shown (axis Y2) is heavily weighted in favor of electromorphs that are unique to the $K$. lactis subgroup and absent 


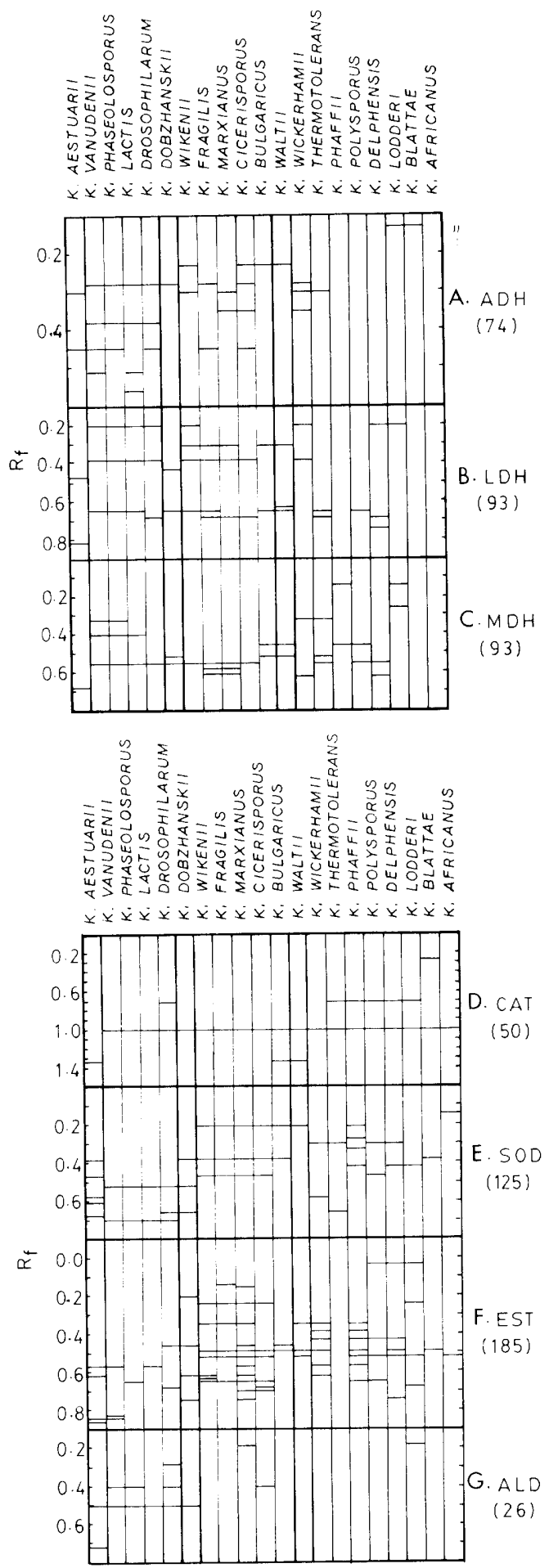

in $K$. aestuarii. The most highly correlated electromorphs were found in several enzymes (in particular, the dehydrogenases, superoxide dismutase, esterase, exo- $\beta$-glucanase, and aldol-

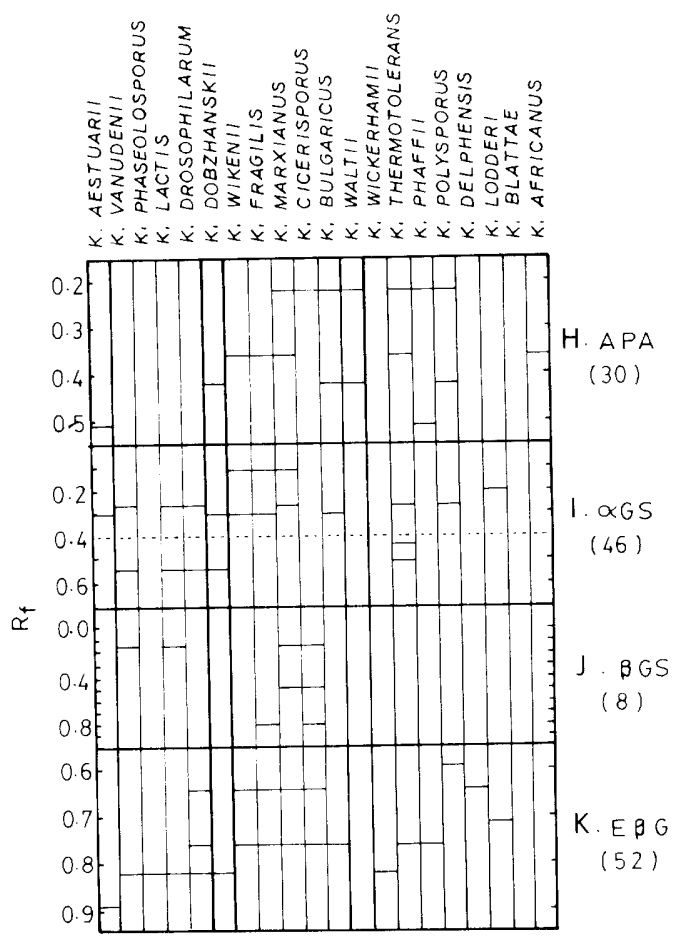

FIG. 1. Electrophoretic patterns of Kluyveromyces type strains for 11 enzyme activities. See the test for a description of the conditions used. The numbers in parentheses are the entropy values $\left(I_{j}\right)$ for each enzyme system. The $\alpha$-glucosidase activities are partitioned according to the specificities of the electromorphs for trehalose and maltose. Abbreviations: $\mathrm{ADH}$, alcohol dehydrogenase; LDH, lactate dehydrogenase; $\mathrm{MDH}$, malate dehydrogenase; CAT, catalase; SOD, superoxide dismutase; EST, esterase: ALD, aldolase; APA, alkaline phosphase; $\alpha \mathrm{GS}, \alpha-$ glucosidase; $\beta \mathrm{GS}, \beta$-glucosidase; $\mathrm{E} \beta \mathrm{G}$, exo- $\beta$-glucanase.

ase: the scores of electromorphs were not plotted for purposes of clarity). The second axis shown (axis Y4) also discriminates strongly between the members of the $K$. marxianus and $K$. lactis DNA subgroups. This axis is compounded mostly by electromorphs that are unique to $K$. lodderi. Most enzymes involved in the $\mathrm{Y} 2$ axis also showed high canonical correlations with the trends elicited by the $\mathrm{Y} 4$ axis.

Other axes (Y1, Y3, Y5 [data not shown]) also separated the $K$. marxianus and $K$. lactis subgroups. Altogether, the first five axes accounted for $51 \%$ of the data structure. Some of the properties are summarized in Table 2 . In each case, the two DNA subgroups represented mutually exclusive statistical populations $(P<$ $0.01)$. The canonical correlations were significant $(P<0.01)$, and the most unusual taxa elicited were not members of either subgroup. 


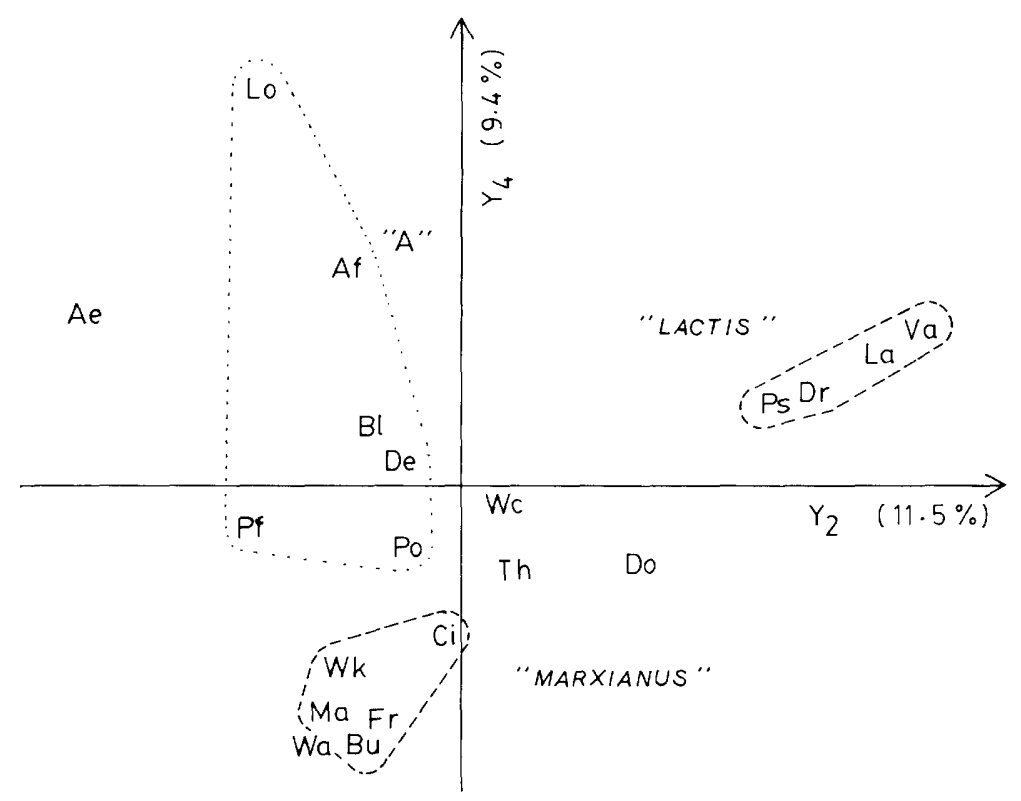

FIG. 2. Ordination of Kluyveromyces type strains by reciprocal averaging. The percentage of the canonical structure represented is indicated for each axis. The dashed lines define phenetic group $\mathrm{A}$ and the $K$. lactis and $K$. marxianus DNA subgroups (Table 1). Abbreviations: Ae, $K$. aestuarii; Af, K. africanus; Bl, K. blattae; Bu, $K$. bulgaricus; $\mathrm{Ci}, K$. cicerisporus; De, K. delphensis; Do, $K$. dobzhanskii; Dr, $K$. drosophilarum; Fr, $K$. fragilis: La, K. lactis; Lo, K. lodderi; Ma, K. marxianus; Pf, K. phaffi; Ps, K. phaseolosporus; Po, K. polysporus; Th, K. thermotolerans; Va, K. vanudenii; Wa, K. waltii; Wc, K. wickerhamii; Wk, K. wikenii.

The overwhelming conclusion of the analyses described above is that the $K$. lactis and $K$. marxianus DNA subgroups must be regarded as evolutionary distinct populations (biological species), despite their ability to mate under laboratory conditions. In terms of nomenclature, the retention of $K$. lactis (with up to four varieties) and $K$. marxianus (with up to five varieties) as separate species would provide species delineation that is consistent with speciation patterns. Verification of these suggestions should derive from electrophoretic studies of populations of strains belonging to these taxa to assess varietal homogeneity. The type strains themselves obviously do not constitute natural populations, and definitive conclusions must rest on data from larger numbers of natural isolates. In addition, the electrophoretic patterns of the meiotic progeny of interspecific hybrids should be examined to verify whether postmating genetic isolation is operating in addition to presumed ecological factors. Both of these approaches are under investigation in our laboratory.

$K$. dobzhanskii appears to share with $K$. thermotolerans and $K$. wickerhamii a more or less intermediate status, although a closer relationship to the K. lactis subgroup is suspected (Fig.

TABLE 2. Comparison of canonical scores in the $K$. lactis and $K$. marxianus DNA subgroups"

\begin{tabular}{|c|c|c|c|c|c|c|c|c|}
\hline \multirow[t]{2}{*}{$\begin{array}{c}\text { Canonical } \\
\text { axis }\end{array}$} & \multicolumn{2}{|c|}{$\begin{array}{c}\text { K. lactis } \\
\text { subgroup } \\
(n=4)\end{array}$} & \multicolumn{2}{|c|}{$\begin{array}{c}K . \text { marxianus } \\
\text { subgroup } \\
(n=5)\end{array}$} & \multirow[t]{2}{*}{$t^{b}$} & \multirow[t]{2}{*}{$\begin{array}{l}\text { Canonical } \\
\text { correlation }\end{array}$} & \multirow[t]{2}{*}{$\begin{array}{l}\text { Most unusual } \\
\text { taxon }\end{array}$} & \multirow[t]{2}{*}{$\begin{array}{l}\text { Score of most } \\
\text { unusual taxon }\end{array}$} \\
\hline & $\bar{Y}$ & $s^{2}$ & $\bar{Y}$ & $\sqrt{s^{2}}$ & & & & \\
\hline 1 & 3.4 & 6.7 & -3.5 & 5.8 & 4.1 & 0.76 & $K$ aestuarii & 42.0 \\
\hline 2 & 16.6 & 9.1 & -4.2 & 3.8 & 11.9 & 0.74 & $K$. aestuarii & -17.3 \\
\hline 3 & -0.4 & 0.4 & 3.1 & 2.4 & 4.6 & 0.68 & K. africanus & 15.4 \\
\hline 4 & 5.0 & 2.3 & -7.7 & 2.4 & 12.4 & 0.66 & K. lodderi & 16.0 \\
\hline 5 & -0.8 & 0.0 & -4.5 & 2.1 & 8.2 & 0.60 & K. phaffii & 10.8 \\
\hline
\end{tabular}

a $\bar{Y}$, Mean $Y$ value; $s^{2}$, variance of $Y ; t$, Student's $t$ test.

${ }^{b}$ The critical $t$ value $(P=0.01 ; \mathrm{df}=7)$ was 3.5 . 
1 and 2). The singular electrophoretic similarity between $K$. waltii and $K$. bulgaricus was unexpected. because members of the former taxon show a remarkable degree of morphological, physiological, and ecological similarity to $K$. thermotolerans, whereas $K$. bulgaricus is more similar to members of the $K$. marxianus DNA subgroup. At this point, we do not propose to unify these two taxa or to incorporate $K$. waltii as a variety of $K$. marxianus.

The status of $K$. drosophilarum is of special interest. As noted previously (16), the type strain exhibits exo- $\beta$-glucanase electromorphs that are found in both the $K$. lactis and $K$. marianus subgroups, although microcomplement fixation (12) only detected enzyme relatedness to the K. lactis subgroup. K. drosophilarum also exhibited special electrophoretic similarities to K.dobzhanskii (Fig. $1 \mathrm{E}$ and $\mathrm{F}$ ) and to $K$. thermotolerans and some members of phenetic group A (Fig. 1D). The level of DNA relatedness of $K$. drosophilartum to other $K$. lactis subgroup strains was estimated at 70\% (13; Phaff et al., Abstr. 12th Int. Congr. Microbiol.), which is unusual. One might speculate that $K$. drosophilarum is a natural hybrid or that it represents a slowly evolving "ancestral" form. It is not clear how this question can be clarified.

Conclusions. The evolutionary taxonomy of Kluyveromyces species is complicated by varying degrees of homothallism in most of the species (18). The coordinate use of many methodological approaches will be required to accomplish sound species delineation based on the speciation process itself. Allopatric speciation is an often ignored alternative to genetic isolation due to loss of mating compatibility. Evidence that groups of strains constitute mutually exclusive ensembles of independent characters which are not directly influenced by natural selection (e.g., the electrophoretic mobilities of certain enzymes) can be used to reconstitute a fragment of their evolutionary history. We have shown, at least with the type strains of Kluyveromyces species, that interfertile strains belonging to different DNA complementarity groups also appear to be distinct evolutionary groups. This finding does not necessarily rule out other types of speciation, such as reticulate evolution, and makes the genus Kluyveromyces all the more interesting as a taxonomic and evolutionary model.

\section{ACKNOWLEDGMENT}

This work was funded by an operating grant from the Natural Science and Engineering Research Council of Canada to M.A.L.

\section{LITERATURE CITED}

1. Baptist, J. N., and C. P. Kurtzman. 1976. Comparative enzyme patterns in Cryptococcus latentii and its taxonomic variants. Mycologia 68:1195-1201.

2. Berchev, K., and K. Izmirov. 1967. Isoenzymes of oxidoreductases in the Candida genus as a basis of species identification after electrophoresis. Experientia 23:961962.

3. Davis, B. J. 1964. Disc electrophoresis. IJ. Method and application to human serum proteins. Ann. N.Y. Acad. Sci. 121:404-427

4. Dickson, R. C., L. D. Dickson, and J. S. Markin. 1978 Purification and properties of an inducible $\beta$-galactosidase isolated from the ycast Kluveromyces lactis. J. Bacteriol. 137:51-61

5. Douglas, H. C., D. P. Grindall, and H. Talbott. 1969. Electrophoretic variants of phosphoglucomutase in $S$ accharomyces species. J. Bacteriol. 99:287-290.

6. Eilers, F. I., J. Allen, E. P. Hill, and A. S. Sussman. 1964. Localization of disaccharides in extracts of Neurospora after electrophoresis in polyacrylamide gels. J. Histochem. Cytochem. 12:448-450.

7. Fleming, L. W., and J. D. Duerksen. 1967. Evidence for multiple molecular forms of yeast $\beta$-glucosidase in a hybrid yeast. J. Bacteriol. 94:142-150.

8. Garber, E. D. 1974. Enzymes as taxonomic and genetic tools in Phaseolus and Aspergillas. Isr. J. Med. Sci. 10:268-277.

9. Harris, H., and D. A. Hopkinson. 1976. Handbook of enzyme electrophoresis in human genetics. North-Holland Publishing Co., Amsterdam.

10. Hill, M. O. 1973. Reciprocal averaging, an eigenvector method of ordination. J. Ecol. 61:237-249.

11. Johannsen, E. 1980. Hybridization studies within the genus Klavieromyces van der Walt emend. van der Walt. Antonie van Leeuwenhoek J. Microbiol. Serol. 46:177189.

12. Lachance, M. A., and H. J. Phaff. 1979. Comparative study of molecular size and structure of exo- $\beta$-glucanase from Kinveromyces and other yeast genera: evolutionary and taxonomic implications. Int. J. Syst. Bacteriol. 29:7078 .

13. Martini, A. 1973. Ibridazioni DNA/DNA tra specie di lieviti del genere Klovyeromyces. Ann. Fac. Agrar. Univ. Studi Perugia 28:157-171.

14. Phaff, H. J. 1980. The species concept in yeast: physiologic, morphologic, genetic, and ecological parameters, $p$. 635-643. In G. G. Stewart and I. Russell (ed.), Current developments in yeast research. Pergamon Press, Toronto.

15. Poncet, S. 1973. Taxonomie numerique du genre Kluveromyces, Mycopathol. Mycol. Appl. 51:267-281.

16. Sidenberg, D. G., and M. A. Lachance. 1982. Multiple molecular forms of exo- $\beta$-glucanase in Kloyreromyces species. Exp. Mycol. 6:84-89.

17. Sneath, P. H. A., and R. R. Sokal. 1973. Numerical taxonomy. W. H. Freeman, San Francisco.

18. van der Walt, J. P. 1970. Kluyveromyces van der Walt emend. van der Walt, p. 316-378. In J. Lodder (ed.), The yeasts, a taxonomic study. North-Holland Publishing Co.. Amsterdam.

19. van der Walt, J. P., and E. Johannsen. 1979. A comparison of interfertility and in vitro DNA-DNA reassociation as criteria for speciation in the genus Klayveromyces. Antonie van Leeuwenhoek J. Microbiol. Serol. 45:281291.

20. Yamazaki, M., and K. Komagata. 1981. Taxonomic significance of electrophoretic comparison of enzymes in the genera Rhodotorula and Rhodosporidium. Int. J. Syst. Bacteriol. 31:361-381. 